\title{
Correction to: Determining Inorganic and Organic Phosphorus
}

\author{
Jaana Koistinen, Mervi Sjöblom, and Kristian Spilling
}

\section{Correction to:}

Chapter "Determining Inorganic and Organic Phosphorus" in: J. Koistinen et al., Methods in Molecular Biology https://doi.org/10.1007/7651_2017_104

There are three corrections for this chapter:

On page 90, 12th line from top, the phrase '(see step 6) with ultrapure water (e.g., 1 ml' has been changed to '(see step 6) with ultrapure water (e.g., $0.1 \mathrm{ml}$ '.

On page 91, 19th line from top, the phrase ' $2 \mathrm{ml}$ in $100 \mathrm{ml}$ ultrapure water for $620 \mu \mathrm{g} \mathrm{P} / 1$ solution)' has been changed to ' $0.2 \mathrm{ml}$ in $100 \mathrm{ml}$ ultrapure water for $620 \mu \mathrm{g} \mathrm{P} / 1$ solution)'.

On page 93, 10th line from top, the phrase 'pure water (e.g., 2-100 ml for $620 \mu \mathrm{g} \mathrm{P} / 1$ solution)' has been changed to 'pure water (e.g., $0.2 \mathrm{ml}$ in $100 \mathrm{ml}$ for $620 \mu \mathrm{g} \mathrm{P} / 1$ solution)'.

These changes have now been updated.

The updated online version of this protocol can be found at https://doi.org/10.1007/7651_2017_104 